\title{
Anthracnose Fruit Rot Resistance in Blueberry Cultivars
}

James J. Polashock, Research Plant Pathologist, Mark K. Ehlenfeldt, Research Geneticist, and Allan W. Stretch, Research Plant Pathologist (retired), USDA-ARS, Fruit Laboratory, Henry A. Wallace Agricultural Research Center, Beltsville, MD 20705 and Matthew Kramer, USDA-ARS, Biometrical Consulting Service, Henry A. Wallace Agricultural Research Center, Beltsville, MD 20705

\begin{abstract}
Polashock, J. J., Ehlenfeldt, M. K., Stretch, A. W., and Kramer, M. 2005. Anthracnose fruit rot resistance in blueberry cultivars. Plant Dis. 89:33-38.

Anthracnose fruit rot (causal agent, Colletotrichum acutatum) is an important disease in most blueberry growing regions of North America. Losses caused by the disease are usually seen as a postharvest rot with orange spore masses appearing on the surface of affected fruit. One hundred cultivars/selections of blueberry were screened for resistance to fruit rot between 1993 and 2003 by inoculating container-grown plants bearing green fruit. Visible rot symptoms on ripe fruits were evaluated after a 1-week incubation at room temperature. Our analyses revealed that infection levels were affected by mean May temperatures in New Jersey, generally increasing as temperatures increased; however, this effect was not consistent among all cultivars. A generalized linear mixed model was developed to predict resistance at the historic mean May temperature, conservatively explaining 59\% of the variance in resistance. Percent infection ranged from 9 to $91 \%$ with a mean of $51 \%$ across all cultivars. Results for common cultivars corresponded well with field reports of their relative susceptibilities. An estimate of narrow-sense heritability of 0.32 suggested additive inheritance of resistance. Since very high inoculum loads were used in this study, cultivars exhibiting a low percentage of fruit rot are predicted to show superior field resistance to the disease and will be incorporated into an ongoing breeding program.
\end{abstract}

Additional keywords: screening, Vaccinium spp.

Anthracnose fruit rot of blueberry (Vaccinium spp.), caused by Colletotrichum acutatum J.H. Simmonds, is an important disease problem in New Jersey (13), North Carolina (1), Michigan (6), Mississippi (12), and British Columbia (16). The disease affects the commercially important highbush (13), rabbiteye (12), and lowbush (7) blueberries. Anthracnose overwinters as mycelium in dead twigs, which probably serves as the primary inoculum source. Recently, the fungus has been reported to overwinter in dormant flower buds, which may serve as an important additional source of inoculum (2). Conidia germinate on the surface of infected green fruit and form appressoria. The hyphae penetrate the epidermis but remain dormant until the fruit begin to ripen (1). Rot symptoms develop on ripening fruit and appear as visible orange-colored spore masses on the fruit surface (9). The spores produced on rotting fruit can infect surrounding fruit as

Corresponding author: J. J. Polashock

E-mail:.jpolashock@ars.usda.gov

Accepted for publication 27 July 2004.

DOI: $10.1094 / P D-89-0033$

This article is in the public domain and not copyrightable. It may be freely reprinted with customary crediting of the source. The American Phytopathological Society, 2005. well as vegetative tissues. The infections in vegetative tissues and dormant flower buds serve as a primary source of inoculum for the following year.

Although anthracnose fruit rot can be controlled by fungicide applications, resistant varieties offer an economically sound alternative to chemical control. A primary objective of the USDA smallfruit breeding program is to identify and utilize sources of resistance to fungal diseases. Preliminary reports in a screening of more than 30 northern highbush cultivars showed variation in resistance, but none with complete resistance $(3,14)$. Rooks et al. (11), in an inventory of pest resistance in blueberry in North Carolina, listed only 'Powderblue' (a rabbiteye blueberry cultivar) and 'Morrow' (highbush) as having resistance to anthracnose fruit rot. This study expands the earlier reports of USDA screening $(3,4,14)$ to include 100 blueberry cultivars and selections. In addition to developing a method to rank the resistance of cultivars under controlled conditions, we wanted to identify environmental factors that vary from year to year and affect resistance. We used variance decomposition methods to evaluate the potential of recovering resistant offspring from crosses of cultivars utilized in an ongoing breeding program and to determine which factors most strongly influence resistance.

\section{MATERIALS AND METHODS}

Plant material. Cultivars and numbered selections that were used in this study are listed in Table 1. These include 64 highbush (Vaccinium corymbosum L.) cultivars, 22 southern highbush (southernadapted $V$. corymbosum, usually with some introgressed $V$. darrowi Camp and/or $V$. ashei Reade), 2 lowbush (V. angustifolium Ait.), 7 'half-high' ( $V$. corymbosum $\times V$. angustifolium derivatives), and 5 mixed species derivatives. The selection 11-104 is a sibling of 'Bluecrop' and 'Blueray'; F-72 is a parent of 'Darrow' and is in the pedigree of several other cultivars; E-176 is a hybrid of F-72 × 'Berkeley'; 'Hardyblue' is a trade name for an old selection from Whitesbog, NJ, originally developed under the number 1613-A; 'Wannabe' is a selection of unknown pedigree grown in some areas of Florida. Pedigrees of all of the cultivars have been previously published or are available from the authors.

All plant materials used in this study were maintained at the Philip E. Marucci Center for Blueberry and Cranberry Research, Chatsworth, NJ. Plants were grown in cold frames in 3-liter pots in a 1:1 mixture of peat and sand.

Inoculation and disease rating. $C$. $a c u$ tatum isolates were collected from infected tissue of highbush blueberry in New Jersey. In most cases, different sets of fresh isolates were used every year to ensure isolate viability and virulence. Only in 1995 and 1996 was the same set of isolates used. Isolates were grown on solid V8 juice agar (1 liter contains $3 \mathrm{~g}$ of $\mathrm{CaCO}_{3}$, $200 \mathrm{ml}$ of $\mathrm{V} 8$ juice, $15 \mathrm{~g}$ of Difco Bactoagar, and $800 \mathrm{ml}$ of $\mathrm{dH}_{2} \mathrm{O}$ ) and allowed to sporulate. Spores were scraped from the plates with a sterile loop and transferred to Erlenmeyer flasks, each containing $50 \mathrm{ml}$ of clarified V8 juice medium $3.75 \mathrm{~g}$ of $\mathrm{CaCO}_{3}$ is added to $250 \mathrm{ml}$ of $\mathrm{V} 8$ juice, stirred for $10 \mathrm{~min}$, centrifuged at 5,400 $\times g$ for $12 \mathrm{~min}$, and $200 \mathrm{ml}$ of supernatant was added to $800 \mathrm{ml}$ of $\mathrm{dH}_{2} \mathrm{O}$ ). Flasks were incubated at room temperature for 2 days on a rotary shaker set to $200 \mathrm{rpm}$. Spores were collected from the liquid medium by centrifugation $(10,000 \times g)$. Spore pellets were each resuspended in $20 \mathrm{ml}$ of sterile water, and spores from 8 to 10 flasks were pooled. Spore quantity was estimated using a hemacytometer and diluted to a final concentration of $1 \times 10^{6}$ spores per ml. Container-grown plants (2 to 5 per cultivar) 
Table 1. Blueberry genotypes used in anthracnose fruit rot evaluations, abbreviations, germplasm type and proportion of decayed berries (modeled at $\left.17.3^{\circ} \mathrm{C}\right)$, standard deviations and modeling coefficients

\begin{tabular}{|c|c|c|c|c|c|c|c|}
\hline \multirow[b]{2}{*}{ Genotype } & \multirow[b]{2}{*}{ Abbrev.v } & \multirow{2}{*}{$\begin{array}{c}\text { Germplasm } \\
\text { type }^{w}\end{array}$} & \multirow[b]{2}{*}{ Years tested } & \multirow{2}{*}{$\begin{array}{c}\text { Proportion } \\
\text { decayed }^{x}\end{array}$} & \multirow[b]{2}{*}{ Std. dev. ${ }^{y}$} & \multicolumn{2}{|c|}{ Parameter estimates $^{\mathrm{z}}$} \\
\hline & & & & & & $\mathbf{C}_{i}$ & $\boldsymbol{\beta}_{i}$ \\
\hline $11-104$ & 11104 & HB & $93,94,95,97$ & 0.68 & 0.38 & -4.27 & 0.19 \\
\hline Angola & ANG & $\mathrm{HB}$ & $93,94,95$ & 0.51 & 0.97 & 8.30 & -0.49 \\
\hline Atlantic & ATL & HB & $96,97,01$ & 0.68 & 0.52 & 3.35 & -0.26 \\
\hline Avonblue & AVN & SHB & $98,00,01,02$ & 0.47 & 0.69 & -6.43 & 0.35 \\
\hline Berkeley & BER & $\mathrm{HB}$ & $93,94,95,97$ & 0.45 & 0.58 & -5.06 & 0.29 \\
\hline Bluecrop & $\mathrm{BC}$ & HB & $93,94,95,97,98,00$ & 0.78 & 0.57 & -6.44 & 0.28 \\
\hline Blue Rose & $\mathrm{BRO}$ & HB & 02 & 0.16 & $\ldots$ & $\ldots$ & $\ldots$ \\
\hline Bluechip & $\mathrm{BCH}$ & $\mathrm{HB}$ & $96,98,00$ & 0.71 & 0.51 & -5.55 & 0.26 \\
\hline Bluegold & BGO & $\mathrm{HB}$ & $93,94,95,97$ & 0.54 & 0.23 & -2.37 & 0.11 \\
\hline Bluehaven & BHV & HB & $93,01,02,03$ & 0.28 & 1.41 & 12.88 & -0.71 \\
\hline Bluejay & BJA & HB & All but $98,00,01$ & 0.43 & 0.66 & -5.70 & 0.33 \\
\hline Blueray & BRA & HB & All but $98,00,01$ & 0.70 & 0.55 & -5.73 & 0.27 \\
\hline Blue Ridge & BRG & SHB & 98,00 & 0.18 & 1.97 & 18.12 & -0.98 \\
\hline Bluetta & BTA & $\mathrm{HB}$ & All but $98,00,01$ & 0.88 & 0.09 & -1.29 & -0.05 \\
\hline Bonus & BNS & HB & $01,02,03$ & 0.43 & 0.06 & 0.62 & -0.04 \\
\hline Brigitta Blue & BGT & HB & $98,00,01,02$ & 0.18 & 0.45 & -2.63 & 0.22 \\
\hline Brunswick & BWK & LB & 02 & 0.61 & $\ldots$ & $\ldots$ & $\ldots$ \\
\hline Cabot & $\mathrm{CAB}$ & $\mathrm{HB}$ & $93,94,95,97$ & 0.39 & 0.09 & 0.97 & -0.05 \\
\hline Cape Fear & CAF & SHB & $98,00,01$ & 0.91 & 2.20 & -21.89 & 1.11 \\
\hline Cara's Choice & $\mathrm{CAC}$ & $\mathrm{HB}$ & $01,02,03$ & 0.63 & 1.11 & -10.41 & 0.55 \\
\hline Chanticleer & CHT & HB & $98,01,02$ & 0.81 & 0.78 & -8.32 & 0.39 \\
\hline Chippewa & $\mathrm{CHP}$ & $\mathrm{HH}$ & $98,00,01$ & 0.71 & 2.09 & -19.45 & 1.05 \\
\hline Collins & $\mathrm{COL}$ & HB & $96,97,00$ & 0.33 & 1.00 & -8.10 & 0.50 \\
\hline Concord & $\mathrm{CON}$ & $\mathrm{HB}$ & 02,03 & 0.58 & 1.30 & -11.64 & 0.64 \\
\hline Cooper & $\mathrm{COO}$ & SHB & $98,00,01$ & 0.82 & 1.53 & -15.04 & 0.77 \\
\hline Croatan & $\mathrm{CRO}$ & $\mathrm{HB}$ & $94,95,01$ & 0.66 & 0.55 & 3.86 & -0.27 \\
\hline Darrow & DAR & HB & $96,97,01$ & 0.63 & 0.08 & -0.10 & -0.04 \\
\hline Dixi & DIX & HB & $96,97,01$ & 0.62 & 0.30 & 1.85 & -0.15 \\
\hline Duke & DUK & $\mathrm{HB}$ & All but $98,00,01$ & 0.44 & 0.37 & -3.21 & 0.18 \\
\hline Duplin & DUP & SHB & 02 & 0.58 & $\ldots$ & $\ldots$ & $\ldots$ \\
\hline E-176 & E176 & $\mathrm{HB}$ & $93,94,95,97$ & 0.65 & 0.47 & -4.90 & 0.24 \\
\hline Earliblue & ERB & $\mathrm{HB}$ & $93,94,95,97$ & 0.68 & 2.45 & 2.61 & -0.21 \\
\hline Elizabeth & ELZ & $\mathrm{HB}$ & $93,98,00,01$ & 0.28 & 0.46 & 4.53 & -0.22 \\
\hline Elliott & ELL & HB & All but 01 & 0.15 & 0.12 & 0.43 & 0.06 \\
\hline F-72 & F72 & HB & $94,95,97$ & 0.45 & 0.24 & -2.12 & 0.12 \\
\hline Flordablue & FLB & SHB & $98,00,01$ & 0.14 & 1.37 & 13.31 & -0.68 \\
\hline Friendship & FRI & $\mathrm{HH}$ & $98,00,01$ & 0.19 & 1.93 & 17.42 & -0.95 \\
\hline Fundy & FUN & LB & 02 & 0.68 & $\ldots$ & $\ldots$ & $\ldots$ \\
\hline Georgiagem & GAG & SHB & $98,00,01$ & 0.49 & 0.26 & -2.81 & 0.14 \\
\hline Grover & GRO & HB & $98,00,01$ & 0.46 & 0.39 & 3.17 & -0.19 \\
\hline Gulfcoast & GUL & SHB & $98,00,01$ & 0.53 & 0.34 & 2.34 & -0.16 \\
\hline Hannah's Choice & HAC & HB & 01,03 & 0.32 & 0.66 & 6.44 & -0.34 \\
\hline Harding & HDG & HB & $93,94,95,97$ & 0.36 & 1.47 & -12.42 & 0.74 \\
\hline Hardyblue & HDY & $\mathrm{HB}$ & $96,97,01,02$ & 0.72 & 0.07 & -0.61 & -0.03 \\
\hline Harrison & HRN & HB & $98,00,01$ & 0.39 & 1.90 & 16.54 & -0.94 \\
\hline Herbert & HER & $\mathrm{HB}$ & $98,00,01$ & 0.70 & 0.60 & -6.37 & 0.31 \\
\hline Ivanhoe & IVH & HB & $96,98,00$ & 0.45 & 1.43 & 12.44 & -0.71 \\
\hline Jersey & JER & HB & $93,94,95,97$ & 0.38 & 0.32 & -2.58 & 0.16 \\
\hline Jewel & JEW & SHB & 02 & 0.73 & $\ldots$ & $\ldots$ & $\ldots$ \\
\hline Jubilee & JUB & SHB & 02 & 0.50 & $\ldots$ & $\ldots$ & $\ldots$ \\
\hline June & JUN & $\mathrm{HB}$ & $93,94,95,97$ & 0.72 & 0.97 & -9.57 & 0.48 \\
\hline Katherine & KAT & HB & $96,97,02$ & 0.55 & 0.39 & 2.75 & -0.19 \\
\hline Lateblue & LAB & $\mathrm{HB}$ & $93,94,95,97$ & 0.55 & 0.02 & -0.60 & 0.01 \\
\hline Legacy & LEG & $\mathrm{HB}$ & $98,00,01$ & 0.10 & 1.86 & 17.68 & -0.91 \\
\hline Little Giant & LIG & RE-CON & $98,00,01$ & 0.09 & 3.04 & 28.33 & -1.52 \\
\hline Magnolia & MAG & SHB & 02,03 & 0.43 & 1.00 & -7.95 & 0.46 \\
\hline Marimba & MAR & SHB & $98,00,01$ & 0.75 & 0.97 & 5.89 & -0.42 \\
\hline Meader & MDR & $\mathrm{HB}$ & $93,94,95,97$ & 0.70 & 0.09 & -0.34 & -0.04 \\
\hline Misty & MIS & SHB & $98,00,01$ & 0.52 & 0.77 & -8.56 & 0.47 \\
\hline Morrow & MOR & $\mathrm{HB}$ & 97,03 & 0.52 & 0.12 & -1.32 & 0.06 \\
\hline Murphy & MUR & $\mathrm{HB}$ & $94,95,96,97$ & 0.39 & 0.61 & -5.08 & 0.30 \\
\hline \multirow[t]{2}{*}{ Nelson } & NEL & $\mathrm{HB}$ & $93,94,95,96,97,01$ & 0.50 & 0.11 & -1.09 & 0.05 \\
\hline & & & & & & \multicolumn{2}{|c|}{ (continued on following pag } \\
\hline
\end{tabular}

v Abbreviations corresponding to those used in Figure 1.

${ }^{w}$ Abbreviations for type, as described in the text. $\mathrm{HB}=$ highbush; $\mathrm{SHB}=$ southern highbush; $\mathrm{LB}=$ lowbush; $\mathrm{HH}=$ half high; $\mathrm{OR}=$ ornamental; $\mathrm{RE}-\mathrm{CON}=$ rabbiteye (Vaccinium ashei)/V. constablaei hybrid; SHB-RE = southern highbush/rabbiteye hybrid.

${ }^{x}$ Estimated proportion of decayed fruit from model for a mean May temperature of $17.3^{\circ} \mathrm{C}$, back-transformed from the logit scale to the proportion scale.

y Standard deviation of decayed fruit estimates from three different May temperatures, providing a measure of the cultivar's stability in resistance over years (on the logit scale).

${ }^{\mathrm{z}}$ The model predicting the logit of the proportion of sound berries is logit $\left(p_{i}\right)=0.03347 \sqrt{ } n_{i}+\beta_{i} T+C_{i}$, where $i$ represents the cultivar, $n$ is the number of berries collected from the bush, $\beta_{i}$ is the May temperature coefficient for cultivar $i, T$ is the average May temperature (in degrees $\mathrm{C}$ ), and $C_{i}$ is the intercept for cultivar $i$. 
Table 1. (continued from preceding page)

\begin{tabular}{|c|c|c|c|c|c|c|c|}
\hline \multirow[b]{2}{*}{ Genotype } & \multirow[b]{2}{*}{ Abbrev. ${ }^{\mathrm{v}}$} & \multirow{2}{*}{$\begin{array}{c}\text { Germplasm } \\
\text { type }^{w}\end{array}$} & \multirow[b]{2}{*}{ Years tested } & \multirow{2}{*}{$\begin{array}{c}\text { Proportion } \\
\text { decayed }^{\mathrm{x}}\end{array}$} & \multirow[b]{2}{*}{ Std. dev. ${ }^{\mathbf{y}}$} & \multicolumn{2}{|c|}{ Parameter estimates $^{\mathrm{z}}$} \\
\hline & & & & & & $\mathrm{C}_{i}$ & $\boldsymbol{\beta}_{i}$ \\
\hline Northblue & NOB & $\mathrm{HH}$ & $93,94,97$ & 0.64 & 0.11 & -1.86 & 0.05 \\
\hline Northcountry & $\mathrm{NOC}$ & $\mathrm{HH}$ & $98,00,01$ & 0.58 & 1.01 & -10.88 & 0.58 \\
\hline Northland & NOL & $\mathrm{HB}$ & $97,02,03$ & 0.38 & 0.71 & -6.02 & 0.36 \\
\hline Northsky & NOS & $\mathrm{HH}$ & $93,94,95,07$ & 0.40 & 0.94 & -8.14 & 0.47 \\
\hline November Glow & NOV & OR & 02 & 0.14 & & & \\
\hline Nui & NUI & $\mathrm{HB}$ & $98,00,01$ & 0.70 & 1.47 & -15.17 & 0.81 \\
\hline O’Neal & ONE & HB & $98,00,01$ & 0.43 & 0.11 & -2.29 & 0.13 \\
\hline Olympia & OLY & HB & $98,00,01$ & 0.55 & 0.32 & -4.53 & 0.23 \\
\hline Ornablue & ORN & OR & $98,00,01$ & 0.55 & 1.82 & -17.66 & 0.98 \\
\hline Ozarkblue & OZB & SHB & $01,02,03$ & 0.55 & 1.54 & -13.35 & 0.74 \\
\hline Patriot & PAT & HB & $93,94,95,97$ & 0.58 & 0.14 & -1.80 & 0.07 \\
\hline Pearl River & PRV & SHB-RE & 02,03 & 0.81 & 0.64 & -7.41 & 0.34 \\
\hline Pemberton & PEM & HB & $93,96,98,00$ & 0.61 & 1.00 & -9.61 & 0.52 \\
\hline Pender & PEN & SHB & 02,03 & 0.56 & 1.28 & 10.27 & -0.62 \\
\hline Pioneer & PIO & HB & $93,94,95,97$ & 0.48 & 1.20 & -10.70 & 0.61 \\
\hline Polaris & POL & $\mathrm{HH}$ & $98,00,01$ & 0.86 & 1.80 & -18.85 & 0.96 \\
\hline Puru & PUR & $\mathrm{HB}$ & $98,00,01$ & 0.56 & 1.19 & -12.10 & 0.66 \\
\hline Putte & PUT & $\mathrm{HB}$ & 02 & 0.88 & $\ldots$ & $\ldots$ & $\ldots$ \\
\hline Rancocas & RAN & $\mathrm{HB}$ & $96,98,00$ & 0.60 & 0.38 & -4.94 & 0.24 \\
\hline Reka & REK & HB & $98,00,01$ & 0.45 & 0.56 & -6.37 & 0.35 \\
\hline Reveille & REV & SHB & $98,00,01$ & 0.39 & 0.49 & -5.39 & 0.32 \\
\hline Rubel & RUB & HB & $93,96,97,03$ & 0.41 & 0.48 & -3.96 & 0.23 \\
\hline St. Cloud & STC & $\mathrm{HH}$ & $98,00,01$ & 0.79 & 1.70 & -17.77 & 0.92 \\
\hline Sampson & SAM & SHB & 02 & 0.53 & $\ldots$ & $\ldots$ & $\ldots$ \\
\hline Sapphire & SAP & SHB & 02 & 0.38 & $\ldots$ & $\ldots$ & $\ldots$ \\
\hline Sharpblue & SHB & SHB & $98,00,01$ & 0.23 & 0.03 & 0.59 & 0.01 \\
\hline Sierra & SIE & $\mathrm{HB}$ & $94,95,97$ & 0.52 & 0.18 & 1.29 & -0.09 \\
\hline Spartan & SPA & HB & All but $98,00,01$ & 0.78 & 0.26 & -3.63 & 0.13 \\
\hline Stanley & STN & $\mathrm{HB}$ & All but 93, 01 & 0.37 & 0.24 & -1.77 & 0.12 \\
\hline Star & STR & SHB & 98,00 & 0.39 & 1.44 & -13.88 & 0.80 \\
\hline Sunrise & SNR & HB & $97,01,03$ & 0.47 & 0.31 & -2.59 & 0.14 \\
\hline Sunshine Blue & SUB & SHB & $98,00,01,02$ & 0.12 & 0.46 & -2.60 & 0.23 \\
\hline Tophat & TOP & OR & $98,00,02$ & 0.38 & 0.70 & -5.14 & 0.31 \\
\hline Toro & TOR & $\mathrm{HB}$ & $93,94,95,03$ & 0.57 & 0.11 & 0.60 & -0.06 \\
\hline Wannabe & WAN & SHB & $98,00,01$ & 0.31 & 0.43 & 2.83 & -0.14 \\
\hline Wareham & WAR & HB & $93,94,95,97$ & 0.47 & 0.27 & -2.49 & 0.14 \\
\hline Weymouth & WEY & HB & $94,95,96,98,00$ & 0.33 & 0.18 & -1.95 & 0.13 \\
\hline Wolcott & WOL & $\mathrm{HB}$ & $96,97,01,03$ & 0.40 & 0.89 & -7.48 & 0.44 \\
\hline
\end{tabular}

bearing approximately pea-sized green fruit (actual size varied, with some cultivars such as 'Little Giant' being proportionately smaller) were spray-inoculated to runoff with the spore suspension. Immediately following inoculation, the plants were held in a mist chamber for $48 \mathrm{~h}$ at ambient temperatures (typically 24 to $30^{\circ} \mathrm{C}$ ) and $>95 \% \mathrm{RH}$ and then transferred to a greenhouse. Two plants per cultivar were used as uninoculated controls. The control plants were sprayed with water and were otherwise treated the same as the inoculated plants.

Ripe fruits were harvested on a weekly basis, then incubated for 1 week in sealed plastic containers at room temperature and $100 \% \mathrm{RH}$ to promote visual manifestation of infection. The numbers of decayed and sound fruit were tallied following the incubation period and recorded for each plant and genotype. Anthracnose tests spanned a period from 1993 to 2003. Most cultivars were evaluated over 3 years, although some cultivars in the analysis were screened for fewer (as noted in Table 1). Selected cultivars (e.g., Bluecrop and Blueray) were inoculated for multiple years to provide standards for comparison across years. The numbers of cultivars tested each year are summarized in Table 2 . The cultivars tested in any given year were usually divided into 2 to 4 blocks for inoculation and incubation due to space constraints. Inoculation and incubation dates ranged from 2 to 17 June depending upon relative fruit development.

Statistical analysis. The proportion of sound berries was analyzed using a generalized linear mixed model, using the glimmix SAS version 8.2 (SAS Institute, Cary, NC) macro (17). This macro allows one to fit a mixed model when sampling from an over-dispersed binomial distribution using a penalized quasi-likelihood approach. The binomial distribution was used as the basis for the model because individual berries can be classified as sound or not sound (the great majority of the latter were diseased). In this statistical approach, proportions are not modeled directly, but rather as the logit of the proportion $\{\log [p /(1-p)]\}$, where $p$ is the proportion of sound berries. Since sampling error decreases with larger sample sizes (berry counts), the model gives plants with higher counts more influence on the estimated model parameters. The data were over-dispersed relative to a theoretical binomial distribution, probably because berries from the same plant were not independent with respect to disease state. Diseased berries tend to occur in clusters rather than be randomly distributed on the bushes in field-grown plants. This may have occurred for our plants as well for both natural (e.g., stage of berry ripeness) and methodological (e.g., unequal distribution of inoculum among berries on a plant) reasons.

In preliminary analyses, we examined the effect of monthly rainfall and mean temperatures during the preinoculation development period (April, May, June) on disease incidence. These analyses suggested that, in addition to a random year effect, mean May temperatures were also predictive of disease severity, although its relationship to disease differed among cultivars. Additionally, the number of berries produced by the plant (transformed as the square root) was also predictive (plants producing more berries tended to have a lower proportion of infected berries). Note that the year effect includes year-to-year differences resulting from using different $C$. acutatum sources each year. An addi- 
tional random effect included in our model was plant incubation block, nested within year.

The interaction between May temperatures and cultivars made ranking difficult because a cultivar's rank could (and did) change depending on what May temperature was used. Results are given for the historical mean May temperature $\left(17.3^{\circ} \mathrm{C}\right)$. Because not all cultivars were tested in all years, many did not have representation in years when May temperatures were close to $17.3^{\circ} \mathrm{C}$. Since cultivars responded differently to different May temperatures, we could not confidently predict a cultivar's response to a May temperature for which that cultivar had no observations. Thus, only cultivars that were present in years where May temperatures were close (within $1{ }^{\circ} \mathrm{C}$ ) to $17.3^{\circ} \mathrm{C}$ were used to produce the ranking. Several cultivars were tested in only one year (2002), but that year had a mean May temperature of $17.4^{\circ} \mathrm{C}$ (see Table 2 ). These cultivars were included in the rankings by estimating their resistance in a simpler model containing only those cultivars present in that year (ignoring the random year effect and the $0.1^{\circ} \mathrm{C}$ temperature adjustment).

To provide a measure of how stable a cultivar's resistance was over years with varying May temperatures, we calculated the standard deviation of model estimates for three different temperatures $(15.3,17.3$, and $19.3^{\circ} \mathrm{C}$ ).

Variance decomposition and heritability. Standard variance decomposition methods were used to judge the relative importance of the random (year, block, error) and fixed (cultivar, May temperature, cultivar by May temperature interaction, and number of berries) effects on explaining total variance of the proportion of sound berries (on the logit scale). Due to the nature of the model, the variance accounted for by the fixed effects could not be further partitioned and was calculated by subtracting the sum of the estimated random effects from the total variance.

Among the cultivars analyzed, 49 clones (representing 29 tested parents) had a halfsib relationship. Values for these clones were used to estimate narrow-sense heritability across the 10-year duration of the testing using variance components from a nested half-sib analysis (5). Before conducting this analysis, resistance estimates were produced for parent and progeny cultivars for each year for which data were collected. Raw data were far too noisy for this purpose, especially for plants with low berry counts, where commonly zero or $100 \%$ of the berries were sound. To produce estimates, each year's data were modeled separately in the generalized linear mixed models framework discussed above, with only berry count, cultivar, and block as independent variables, so that estimates across years were independent, rather than filtered through an overall model. These estimates (logits) were then used for the half-sib analysis. In the halfsib analysis, variance components were estimated for parents, progeny nested in parents, replicates within progeny (these are progeny estimates from different years), and year (estimating part of the contribution of environmental variance).

\section{RESULTS}

For a given cultivar, year-to-year variation was often considerable. The only environmental factor found to be a significant predictor of disease incidence was mean May temperature, although this effect differed among cultivars (cultivar by May temperature interaction: $P<0.0001$, $F_{88,2459}=3.89$ ). Plants producing more berries tended to have a lower proportion of infected berries $\left(P<0.0001, F_{1,2511}=\right.$ 53.38). A model predicting the logit of the proportion of sound berries for a given cultivar is logit $\left(p_{i}\right)=0.03347 \sqrt{ } n_{i}+\beta_{i} T+$ $C_{i}$, where the subscript $i$ represents the cultivar, $n$ represents the number of berries collected from the bush, $\beta_{i}$ represents the May temperature coefficient for cultivar $i$, $T$ is the mean May temperature (in degrees $\mathrm{C}$ ), and $C_{i}$ is the intercept for cultivar $i$. To back-transform to the original (proportion) scale, one can use $\exp (x) /[1+\exp (x)]$, where $x=\operatorname{logit}\left(p_{i}\right)$. It was apparent that some cultivars were quite variable across years while others were stable. Standard deviations (SD) estimating this year-toyear variability on the logit scale, for fruit rot on cultivars tested in multiple years, are given in Table 1. Among the cultivars with especially high standard deviations are 'Little Giant', 'Earliblue', 'Cape Fear', and 'Chippewa' (all >2.0). This is in contrast to 'Lateblue', which had the lowest SD value, at 0.02. Cultivars also exhibited differing trends of disease expression (increasing or decreasing proportion of sound berries with increasing average May temperature) across the modeled temperature ranges. The directions of these trends and their magnitude with increasing temperature are given in Table 1 ( $\beta_{i}$ coefficient above).

A variance decomposition showed that this model conservatively accounted for $59 \%$ of the observed variation in anthracnose resistance. This variance decomposition lumps the variance due to sampling error, which can be substantial for small berry counts, with unaccounted-for variation. This estimate is conservative because the total variance can never be completely accounted for with this type of model (10). Of this $59 \%$, most $(93 \%)$ was attributable to the fixed effects, the rest to year-to-year (that part of year-to-year variability due to mean May temperature differences, cultivar by May temperature interactions, and number of berries is included with fixed effects) and block-to-block variation.

Rankings of cultivars modeled at the historic mean May temperature of $17.3^{\circ} \mathrm{C}$ are given in Figure 1. These were backtransformed to the original scale and subtracted from one to yield the estimated proportion of decayed fruit and are displayed with $95 \%$ confidence intervals on the estimate. The size of the confidence interval is a function of sample size, the number of years the cultivar was tested, and the proximity of the proportion to the limits of zero and one (on the logit scale used for the analysis, the confidence limit would be symmetric and not affected by the value of the estimate). Table 1 lists all the blueberry genotypes used in this study alphabetically with their abbreviations (used in Fig. 1) and their estimated parameters for prediction from the model.

Table 2. Summary of design and conditions for tests of resistance of blueberry cultivars to anthracnose fruit rot, 1993 to 2003

\begin{tabular}{|c|c|c|c|c|c|}
\hline Year $^{w}$ & Cultivars $^{\mathrm{x}}$ & Blocks $^{y}$ & $\begin{array}{l}\text { Mean May } \\
\text { Temp. }\left({ }^{\circ} \mathbf{C}\right)\end{array}$ & $\operatorname{Reps} / \mathbf{c v}^{\mathrm{z}}$ & Notes \\
\hline 1993 & 36 & 4 & 19.1 & 2 & Blocks 1 and 2 identical $(20 \mathrm{cv})$; blocks 3 and 4 identical $(16 \mathrm{cv})$ \\
\hline 1994 & 34 & 3 & 16.9 & $2-3$ & Blocks 1 and 2 identical $(33 \mathrm{cv})$; block $3(15 \mathrm{cv})$ \\
\hline 1995 & 33 & 2 & 17.9 & 5 & Blocks 1 and 2 identical $(32 \mathrm{cv})$ \\
\hline 1996 & 27 & 2 & 15.9 & 2 & Block 1 (29 cv); block 2 (19 cv) \\
\hline 1997 & 44 & 4 & 15.3 & 5 & Blocks 1 and 3 identical $(22 \mathrm{cv})$; blocks 2 and 4 identical $(23 \mathrm{cv})$ \\
\hline 1998 & 43 & 4 & 19.0 & 5 & Blocks 1 and 3 identical $(22 \mathrm{cv})$; blocks 2 and 4 identical $(21 \mathrm{cv})$ \\
\hline 2000 & 42 & 4 & 17.8 & 5 & Blocks 1 and 3 identical $(21 \mathrm{cv})$; blocks 2 and 4 identical $(21 \mathrm{cv})$ \\
\hline 2001 & 44 & 4 & 18.2 & 5 & Blocks 1 and 3 identical $(24 \mathrm{cv})$; blocks 2 and 4 identical $(24 \mathrm{cv})$ \\
\hline 2002 & 33 & 4 & 17.4 & 5 & Blocks 1 and 3 identical $(17 \mathrm{cv})$; blocks 2 and 4 identical $(16 \mathrm{cv})$ \\
\hline 2003 & 26 & 1 & 15.8 & 5 & Block 1 had $26 \mathrm{cv}$ \\
\hline
\end{tabular}

w No data were collected in 1999.

${ }^{x}$ Number of cultivars (cv)/selections tested each year.

y Number of tests (blocks) performed each year. A block includes all plants inoculated on a given day.

${ }^{\mathrm{z}}$ Each replicate represents one plant. 
Inoculated fruit infection values averaged $51 \%$ for all selections tested and ranged from about $9 \%$ to about $91 \%$ (Fig. 1). Although the data are generally continuous, a cultivar can be considered to be different from another cultivar if its mean does not overlap the $95 \%$ confidence interval (CI) of the other cultivar. Using this criterion, a group of more resistant cultivars (i.e., means overlapping the $\mathrm{CI}$ of 'Little Giant' [LIG]) with $20 \%$ or less infection, includes LIG through 'Blue Rose' (BRO). Similarly, the most susceptible group includes 'Cape Fear' (CAF) through 'Pearl River' (PRV). This group is considered to be extremely susceptible with more than $85 \%$ infection. An examination of germplasm types $(\mathrm{HB}=$ highbush; $\mathrm{SHB}=$ southern highbush; $\mathrm{LB}=$ lowbush; $\mathrm{HH}=$ half high; $\mathrm{OR}=$ ornamental; RE-CON = rabbiteye $[V$. ashei] $/ V$. constablaei hybrid; SHB-RE = southern highbush/rabbiteye hybrid, as noted in Table 1) among all resistant and susceptible groups suggested that none appeared to occur with any greater frequency in one group or the other.

Variance components for calculating heritabilities were estimated as 0.1082 (parent), 0.1362 (progeny within parent), 0.2678 (replicate), and 0.8470 (year). The estimate for year can be interpreted as part of the contribution of environmental variance. Narrow-sense heritability was calculated as $h^{2}=0.32=4(0.1082) / 1.3592$ across all years of the study, where the denominator is the sum of the variances of parent, progeny within parent, replicate, and year.

Anthracnose fruit rot incidence in the controls (uninoculated) was 1 to $2 \%$ in all cultivars over all years (data not shown). This suggests that the natural levels of anthracnose inoculum in all plants used in this study were quite low.

\section{DISCUSSION}

Year-to-year variation in frequency of infected berries was considerable. Although our evaluations were carried out under relatively controlled conditions, this variability is similar to field data reported by Teodorescu et al. (15). Plants producing more berries tended to have a lower proportion of infected berries. The most direct explanation for this is that more vigorous and "healthy" plants both produce more fruit and are more resistant to disease pressure.

We empirically linked mean May temperatures to disease levels, but we do not have an explanation for the effect or why the effect differs among cultivars. Differences in mean May temperature provide part of the explanation for year-to-year differences seen in the data. The May temperature effect and other factors contributing to year-to-year differences in resistance are likely, in part, to be mediated through physiological and biochemical factors. Cultivars may vary in the susceptibility of these factors to modification by environmental conditions. In cultivars, where the factors contributing to resistance are highly influenced by environmental conditions, one might expect greater year-to-year variability.

It is possible that isolates of $C$. acutatum differ in virulence on different cultivars as noted by Milholland (8), explaining some of the year-to-year variation. The use of different fungal isolates across years ensures that cultivar response is consistent with what might be expected in the field, where inoculum sources vary, but confounds inoculum source with other factors that vary from year-to-year. Cultivars that are both stable across years and exhibit low levels of infection should provide reliable sources of resistance for breeding and inheritance studies.

Rankings based on an overall mean May temperature were calculated. If these rank-

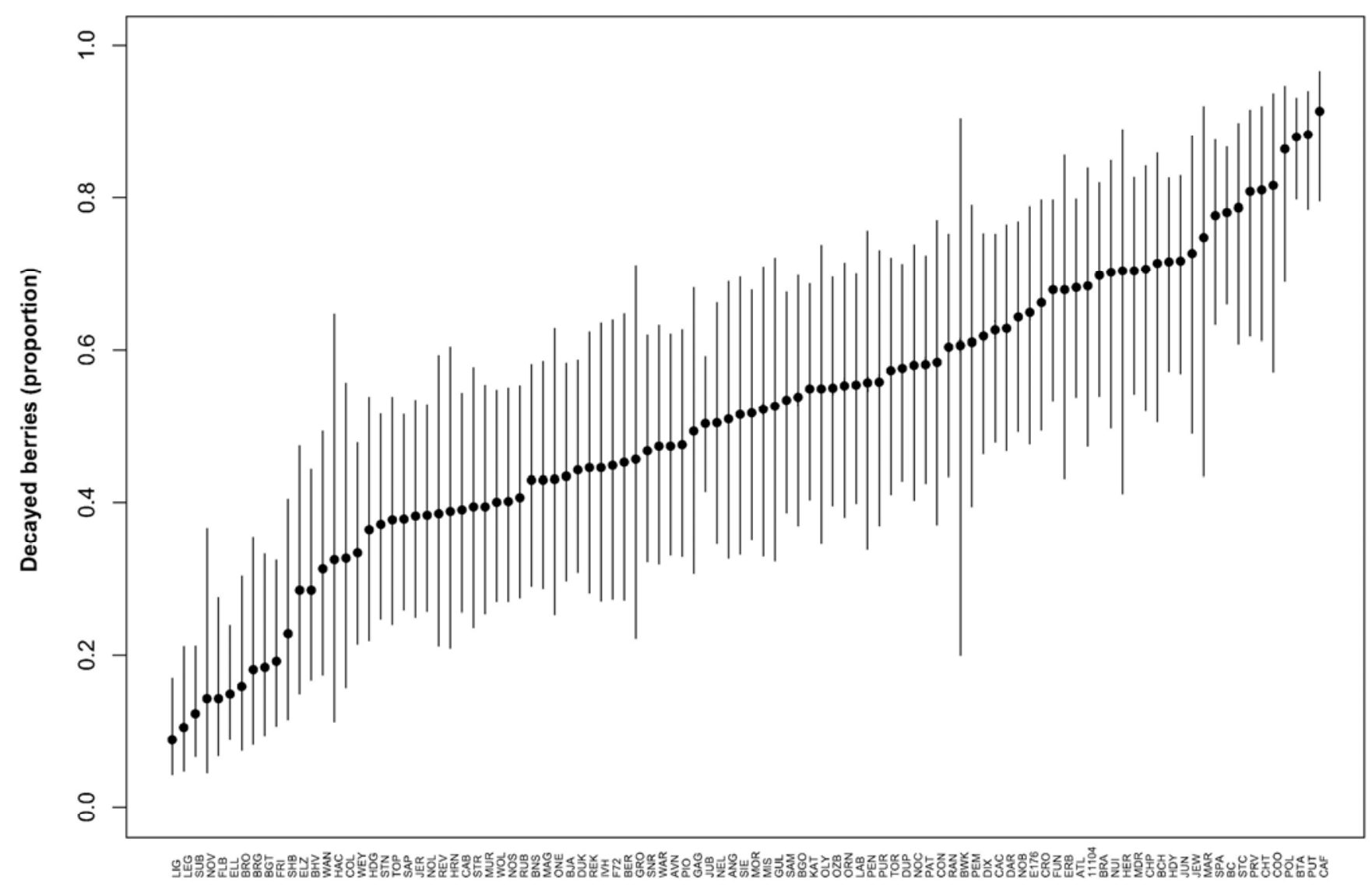

Cultivar

Fig. 1. Point estimates and their $95 \%$ confidence intervals for proportions of anthracnose-decayed berries for 100 blueberry cultivars tested from 1993 to 2003. Estimates are given for the historic mean May temperature of $17.3^{\circ} \mathrm{C}$. Abbreviations used are explained in Table 1. 
ings are well-related to field effects, they should be useful for climates with May temperatures similar to those in New Jersey. Although rankings could change with different temperatures, the confidence intervals are sufficiently large that few of the changes in rank would yield significant changes in relative resistance/susceptibility. Nonetheless, for climates with dissimilar May temperatures, cultivars could be ranked for a different May temperature using the model given above (note that the confidence intervals would increase).

The rankings we derived are consistent with anecdotal reports of cultivar field susceptibility to anthracnose fruit rot, although direct comparisons are difficult since most commercial farms use a fungicide regime. Nonetheless, 'Elliott' for example, has been reported to be very resistant, while 'Bluecrop' has been reported to be very susceptible. In a report on field incidence of anthracnose fruit rot, Teodorescu et al. (15) described very high year-to-year variability over the 3-year study. They reported that 'Atlantic' was the most severely infected of the 22 cultivars assayed and that 'Weymouth' consistently had the lowest level of infection. Our data are in general agreement with this report, with 'Atlantic' among the more susceptible cultivars and 'Weymouth' among the more resistant.

Daykin and Milholland (1), in a test of eight cultivars (using Colletotrichum gloeosporioides), found 'Powderblue' and 'Morrow' resistant, and 'Harrison' and 'Jersey' relatively susceptible. 'Powderblue' was not in our tests, but 'Morrow' ranked near the middle of the range $(52 \%$ infection) and, contrary to Daykin and Milholland, 'Jersey' and 'Harrison' both ranked more resistant than 'Morrow' (38 and $39 \%$, respectively). This discrepancy could be due to differences in fungal inoculum, since Daykin and Milholland (1) used a different species of Colletotrichum. We note that from 1994 to date, only $C$. acutatum has been recovered from anthracnose-infected fruit collected in New Jersey (P. V. Oudemans, personal communication). Similarly, Verma et al. (16) reported that all field isolates from blueberry in British Columbia appeared to be $C$. acutatum.

In addition to the data discussed above, Milholland, in a Vaccinium disease compendium (9), listed the highbush cultivar Blueray as being highly susceptible, and the cultivars Murphy and Reveille as far less susceptible. Our data agree that 'Murphy' and 'Reveille' are moderately resistant (39\% infection) and 'Blueray' is highly susceptible at $70 \%$ infection.

None of the blueberry germplasm types (HB, SHB, LB, OR, etc.) occurred with any greater frequency in either the resistant or susceptible group, suggesting that there is no predictable response to anthracnose infection based on blueberry species ancestry alone. However, since cultivars are highly selected, it does not rule out the possibility of finding significant resistance to anthracnose among blueberry species. No methodical evaluation of individual species populations with respect to anthracnose fruit rot has been reported.

Our heritability estimate of 0.32 suggests that genetic control of anthracnose fruit rot may have a significant epistatic interaction effect along with an additive component. The sibling groups used in the heritability calculations do not represent unselected pairs, as might be desired for an unbiased estimate of heritability, and it is probable that the individuals utilized have undergone some empirical selection for resistance to anthracnose during development and testing. A truly unbiased population sample would probably include more individuals with higher levels of susceptibility and hence might produce an even lower heritability estimate. Our estimate should be interpreted with caution, and should be considered to represent only a biased estimate of the actual heritability values. Based on this estimate, recovery of resistant types from crosses of resistant parents might follow an additive model at best, or may result in a low yield of resistant offspring at worst.

Since year-to-year variation was very high for some cultivars, future research should test cultivars in multiple years with multiple pathogen isolates to separate the pathogen effect from other effects that vary among years. The environmental conditions of each year need to be considered. The cultivars we used were tested under very high inoculum loads and ideal incubation conditions, possibly inflating apparent susceptibility relative to actual field performance. Thus, cultivars found moderately resistant in this study might exhibit adequate or possibly superior field resistance. We believe that the cultivars revealed as resistant under this testing regime represent viable sources of resistance for future breeding. To aid in the utilization of these data in making breeding selections, and to make it more useful to extension personnel, further investigations need to establish how these assay values translate to commercially viable levels of resistance. Further studies of the genetic control of resistance to this disease would also be useful in furthering our ability to select for resistance in offspring populations.

\section{LITERATURE CITED}

1. Daykin, M. E., and Milholland, R. D. 1984 Infection of blueberry fruit by Colletotrichum gloeosporioides. Plant Dis. 68:948-950.

2. DeMarsay, A., and Oudemans, P. V. 2003. Colletotrichum acutatum infections in dormant highbush blueberry buds. (Abstr.) Phytopathology 93:S20.

3. Ehlenfeldt, M. K., and Stretch, A. W. 2001. Blueberry Cultivar Database - Version 2001a Phase 1 - Disease Resistance. USDA-ARS Fruit Laboratory Database CD.

4. Ehlenfeldt, M. K., and Stretch, A. W. 2002. Identifying sources of resistance to mummy berry and anthracnose in highbush, rabbiteye, and species germplasm. Acta Hortic. 574:3138.

5. Falconer, D. S. 1989. Introduction to Quantitative Genetics, 3rd ed. Longman Scientific and Technical, Essex, England.

6. Hartung, J. S., Burton, C. L., and Ramsdell, D. C. 1981. Epidemiological studies of blueberry anthracnose disease caused by Colletotrichum gloeosporioides. Phytopathology 71:449-453.

7. Lambert, D. H. 1990. Postharvest fungi of lowbush blueberry fruit. Plant Dis. 74:285287.

8. Milholland, R. D. 1975. Susceptibility of highbush and rabbiteye blueberry in North Carolina to Glomerella cingulata. Plant Dis. Rep. 59:189-192.

9. Milholland, R. D. 1995. Anthracnose fruit rot (ripe rot). Page 17 in: Compendium of Blueberry and Cranberry Diseases. F. L. Caruso and D. C. Ramsdell, eds. American Phytopathological Society, St. Paul, MN.

10. Nagelkerke, N. J. D. 1991. A note on a general definition of the coefficient of determination. Biometrika 78:691-692.

11. Rooks, S. D., Ballington, J. R., Millholland, R. D., Cline, W. O., and Meyer, J. R. 1995. Inventory of pest resistance in blueberry genotypes in North Carolina. Pages 99-110 in: Blueberries: A Century of Research. Haworth Press, New York.

12. Smith, B. J., Magee, J. B., and Gupton, C. L. 1996. Susceptibility of rabbiteye blueberry cultivars to postharvest diseases. Plant Dis. 80:215-218.

13. Stretch, A. W. 1967. Occurrence and control of Glomerella cingulata on highbush blueberry. Plant Dis. Rep. 51:401-404.

14. Stretch, A. W., and Ehlenfeldt, M. K. 1997 Identifying sources of resistance to mummy berry and anthracnose in highbush blueberry. Acta Hortic. 446:281-286

15. Teodorescu, G., Copaescu, V., and Florea, S. 1985. The behaviour of some blueberry cultivars to the main micoses in Romania. Acta Hortic. 165:159-165.

16. Verma, N., MacDonald, L., and Punja, Z. K. 2003. Epidemiology of blueberry anthracnose in British Columbia and potential options for disease management. (Abstr.) Can. J. Plant Pathol 25:113-114.

17. Wolfinger, R., and O'Connell, M. 1993. Generalized linear mixed models: A pseudolikelihood approach. J. Stat. Comput. Simul. 48:233-243. 